\title{
Grazing Effects of Fish versus Sea Urchins on Turf Algae and Coral Recruits: Possible Implications for Coral Reef Resilience and Restoration
}

\author{
Leor Korzen, ${ }^{1}$ Alvaro Israel, ${ }^{2}$ and Avigdor Abelson ${ }^{1}$ \\ ${ }^{1}$ Department of Zoology, Tel Aviv University, Ramat Aviv 69978, Israel \\ ${ }^{2}$ Israel Oceanographic and Limnological Research Ltd, The National Institute of Oceanography, P.O. Box 3080, \\ Tel Shikmona, Haifa 31080, Israel
}

Correspondence should be addressed to Leor Korzen, leorkorzen@yahoo.com

Received 13 April 2011; Accepted 14 June 2011

Academic Editor: Ricardo Serrão Santos

Copyright (C) 2011 Leor Korzen et al. This is an open access article distributed under the Creative Commons Attribution License, which permits unrestricted use, distribution, and reproduction in any medium, provided the original work is properly cited.

\begin{abstract}
Herbivory is an important structuring factor in coral reefs, influencing seaweed abundance, competitive interactions between seaweeds and corals, and coral reef resilience. Despite reports of a drastic increase in the cover of benthic algae and turf dominancy in the coral reefs of Eilat, Red Sea, very little is known about the factors responsible for this phenomenon or the possible effects of herbivory on turf algae and coral recruits. Here, we examine the effects of herbivory by experimentally exposing turf algae and coral recruits to grazing activities of herbivorous fish and sea urchins. Using remote video cameras to document removal of algae and coral spats, we show that the main grazing impact is due to daily grazing by fishes, whereas the significant impact of sea urchins is mainly expressed in their adverse effect on the survival of coral recruits, with a relatively low effect on algal biomass. These findings contribute to our understanding of the factors influencing turf algae establishment and proliferation, and the survival of coral recruits on the coral reefs of Eilat. The clear differences between the impact of herbivorous fish and that of sea urchins, on the Eilat reefs, have critical implications for reef resilience and restoration measures.
\end{abstract}

\section{Introduction}

The escalating environmental threats and the concern for the future existence of the world's coral reefs have led to increased studies and speculations on coral reef resilience. Resilience has been defined, among others, as the ability of the reefs to absorb recurrent disturbances and subsequently rebuild coral-dominated systems [1]. Resilience is critically dependent on maintaining a balance among the different reef dwellers or functional groups (e.g., algae, corals [2]). Changes in this balance can lead to a phase shift, that is, an alternative assemblage, typically characterized by algal takeover and dominancy [3].

The takeover of coral reefs by algal turf is a process that has significant ecological implications [4]. Algal communities, dominated by highly productive, small filamentous algal turf, can hinder coral settlement and overgrow coral recruits, thus contributing to the demise of a coral population [5].
The factors determining the relative abundance of either corals or algae on coral reefs are most often an outcome of the complex interactions between environmental factors (bottom-up controls such as nutrient levels) and biological factors (top-down controls such as grazing [5-7]).

Herbivory, the removal of plant biomass, is one of the most important structuring factors of benthic communities in general and of coral reefs in particular $[6,8,9]$. Grazing by macroherbivores (notably seaurchins and fish) has profound effects on the distribution and abundance of coral reef algae and corals, by clearing substrates for the re-colonization of coral recruits following disturbances $[10,11]$. Hence, herbivores confer coral resilience to the extent that they exert a grazing impact that maintains a balance between corals and algae.

Resilience is also reflected in the ability of reef communities to regenerate to their previous state through successful larval recruitment and growth [12]. The low recruitment 
success of reef corals is widely assumed to be due to poor survival of recruits during their early life stages $[13,14]$. Although diverse studies have attempted to characterize the dynamics of coral recruitment, elucidating the exact effects of grazing on the mortality of coral recruits has proven challenging, due to the inherent technical difficulties in observing them. While grazing has been shown to enhance coral recruitment through the consumption of seaweeds and consequent reduction of competitive pressure [15-17], grazing may also cause coral mortality during the early stages of development [18]. Although some studies have shown the effects of grazers on coral recruitment [19], no direct observations of coral removal have been made to date [17, $20,21]$, and the exact effect of grazers on coral recruitment is still to be determined $[22,23]$.

A prominent example of a degrading coral reef is the coral reef of Eilat, Red Sea. In common with many other reefs around the world [24], the coral reefs of Eilat have experienced a drastic increase in the cover of benthic algae, with algal takeover and turf dominancy commonly being reported for these reefs [25]. Despite the ecological and conservation significance of this phenomenon, little is known about the factors that regulate the proliferation and abundance of turf algae in the Eilat reefs.

The main objectives of this study were to determine which reef grazers are the predominant consumers of turf algae in the coral reefs of Eilat, Red Sea, and how grazing on the turf algae affects the survival of coral recruits. To address these objectives, we studied the effects of grazing (both day and night grazing activities), by experimentally exposing turf algae and juvenile corals to the grazing impacts of herbivorous fish and invertebrates (notably sea urchins).

\section{Materials and Methods}

Grazing experiments were conducted at two sites, $10 \mathrm{~m}$ apart, at $5 \mathrm{~m}$ depth, on a continuous reef flat (Figure 1). Grazer exclusion cages were located on the reef at a depth of $5 \mathrm{~m}$. Each cage was $2,500 \mathrm{~cm}^{2}(50 \times 50 \mathrm{~cm})$ in area and $25 \mathrm{~cm}$ high. The $35 \mathrm{~mm}$ cage mesh excluded all roving fish species greater than $10 \mathrm{~cm}$ total length but permitted access by smaller individuals. There were nine replicate cages. All cages were monitored, and the mesh was cleaned every 14-20 days. Twelve settlement plates were placed in each cage and secured to the bottom mesh, and three additional settlement plates were placed outside each cage as control. Settlement plates were composed of unglazed ceramic tiles, $10 \times 13 \mathrm{~cm}$ in area. Cages were deployed in October 2007. Four months later the mesh was removed, six settlement plates ( 3 caged +3 control) from each cage were removed in sealed plastic bags, and the upper surface was scraped using a metal spatula and frozen for later biomass examination. The remaining settlement plates were used for feeding observations. Following this, clean settlement plates were attached and the mesh was replaced for an additional 4-month period. This procedure was repeated twice, in February 2008 and August 2008. Although the experiments were carried out during different seasons, as the

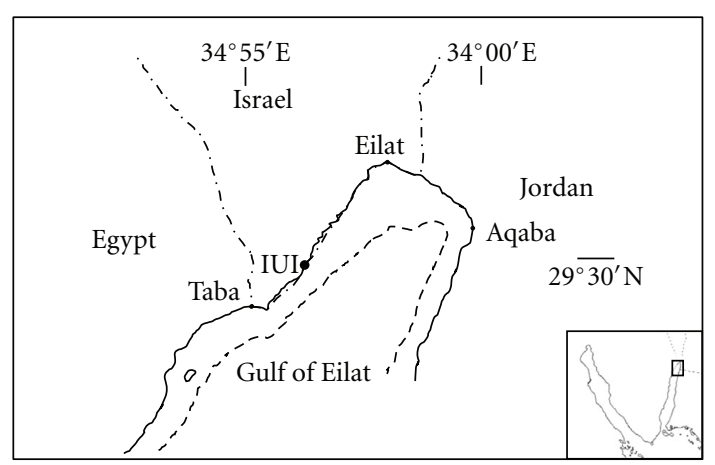

$\begin{array}{ll} & (\mathrm{km}) \\ & 5\end{array}$

FIGURE 1: Study site map. Map showing study site along the coast of Eilat, the northern tip of the Gulf of Aqaba (Eilat), Red Sea:, InterUniversity Marine Institute (IUI).

data obtained showed high statistical resemblance between both experiments, the two data sets have been merged.

2.1. Grazing Effect on Turf Algae. In order to provide direct estimates of herbivore impact on turf algae, algal assays were used to determine turf removal rates after 2 and $11 \mathrm{~h}$ exposure to herbivorous reef grazers. Settlement plates were removed from the mesh cages and placed on the reef at two similar sites, six plates per site. Both sites were on the reef flat, at a depth of $5 \mathrm{~m}$, and were relatively clean of algae. In order to determine the direct feeding impact on turf algae, all other algae than turf were detached and removed. Turf-algal removal trials commenced at $08.00 \mathrm{~h}$. Three plates were removed after two hours and the other three after sunset. In order to determine nocturnal herbivore impact, six additional plates were deployed after sunset. Three of these were removed after two hours and the other three before sunrise. All plates were removed in individual sealed plastic bags, and the upper surface was scraped using a metal spatula and frozen for later biomass examination. This procedure was repeated for three days, totaling 18 replicates for each exposure period ( 3 plates $\times 2$ sites $\times 3$ days). A measure of herbivore abundance and bites taken in the absence of observation divers was obtained using remotely deployed video cameras. Night observations employed underwater illumination (commercial 16 led light bulb placed in a custom-made PVC housing). Each site was illuminated by two led bulbs mounted on the video camera tripod. All light bulbs were connected by shielded twisted pair cables to an onshore power supply and controlled by a digital timer. In order to minimize disturbance from illumination, the timer was set to turn on the lights every $3 \mathrm{~min}$ for a period of $5 \mathrm{sec}$. Video recording commenced one hour before the algal removal trials, in order to provide an estimate of herbivore impact on the natural substrata at both sites. In order to estimate the grazing impact of individual species of herbivore, the entire $288 \mathrm{~h}(2$ sites $\times 24 \mathrm{~h} \times 3$ days $\times 2)$ video footage was viewed and analyzed. Night observations 
were analyzed by recording the number of echinoids (the only species observed grazing at night) on each settlement plate and the total period of time in which the plate had been grazed. Recordings were done during the 5 -secand illumination period every $3 \mathrm{~min}$; if the same echinoid was present on the same settlement plate for the duration of several consecutive intervals, it was considered as grazing throughout the entire period.

The remote video recordings of herbivore bites were used to provide direct estimates of herbivore impact for each of the species. In order to compare our results with other studies, we used the same video sampling methods applied by Fox and Bellwood [26] and Mantyka and Bellwood [27]. The total number of individuals and the total number of bites taken per fish species were recorded. A "bite" was recorded only if the fish was seen to apply its jaws to the algae and close its mouth. Rapid bites in quick succession that could not be separated were counted as a single bite. Bites were not counted if dislodged material was ejected. The effect of different fish sizes on turf algal removal was assessed by dividing individuals of each fish species into seven size classes: $5-7.5,7.6-10,10.1-15,15.1-20,20.1-25,25.1-30$, and $>30 \mathrm{~cm}$ (a quadrate in the field of view prior to filming provided a scale). Total number of bites per fish species was then converted into a standardized bite impact (total bites $\times$ body mass in kilograms) using published lengthweight relationships [28-30], with fish length taken as the midpoint of the respective size class. This enabled focus on the functionally dominant species in the local assemblage.

2.2. Grazing Effect on the Survival of Juvenile Corals. Coralalgal assays were used to study the effect of algal grazing on juvenile corals. Two mesh cages with attached settlement plates were placed at $5 \mathrm{~m}$ depth for a six-month period (April-October 2008). After six months the mesh was removed, and 24 settlement plates tagged with different numbers and 6 control plates were removed in individual plastic bags, for coral detection. The detection of juvenile corals was done using UV flash lights (model Blue Star and BlueBlock and filter for the diving mask by NightSea). Using UV lights allowed detection of young corals hidden beneath a thick algal cover, since many corals exhibit fluorescence [31]. The strong contrast between the black background and the green fluorescence made detection easy and reliable $[32,33]$. The detection took place in shallow tanks of running sea water that were placed in a dark room. The number of corals on the surface of each plate was recorded. In order to determine coral survival rates after 2,12 , and $24 \mathrm{~h}$ exposure to herbivorous reef grazers, 18 tagged plates were brought back and deployed on the reef at two similar sites, nine plates per site. Both sites were on the reef flat, at a depth of $5 \mathrm{~m}$, and were relatively clean of algae. Trials commenced at $16.00 \mathrm{~h}$. For each time interval three plates from each site were removed in individual plastic bags, the number of corals was recorded, and the plate surface was scraped for biomass examination.

2.3. Biomass Examinations. Samples were placed on aluminum cores, dried at $60^{\circ} \mathrm{C}$ for $24 \mathrm{~h}$ (TUTTNAUERL oven), and weighed to determine their dry weight (DW). The

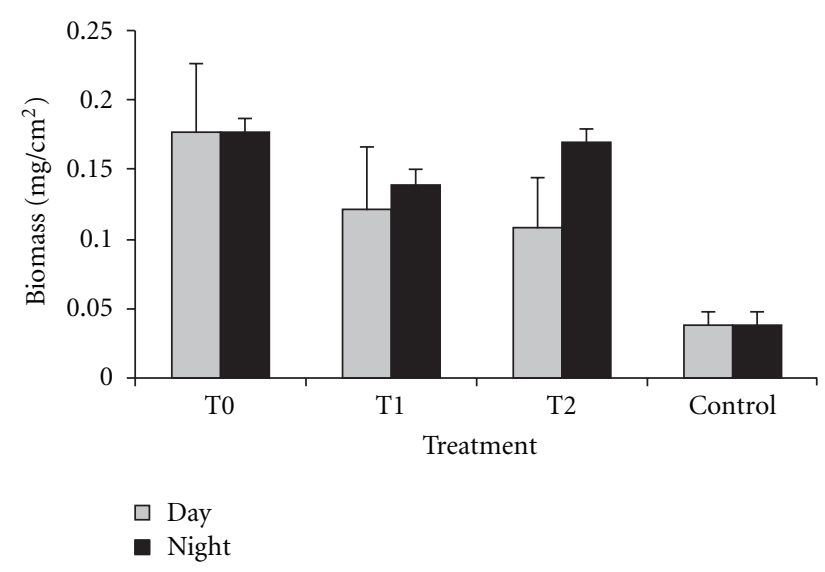

Figure 2: Organic matter as measured in February 2008. Treatments consisted in caged settlement plates (T0 $n=26$ ), noncaged settlement plates (out $n=26$ ), and settlement plates removed from the cages and exposed to grazing for $2 \mathrm{~h}(\mathrm{~T} 1 n=18)$ and $11 \mathrm{~h}$ (T2 $n=18$ ). Grey columns: day exposure, black columns: night exposure.

samples were then burned at a temperature of $45^{\circ} \mathrm{C}$ for $6 \mathrm{~h}$ and were weighed again for their inorganic ash value (AOM). Organic weight (OW) was calculated according to the following formula:

$$
\text { DW minus AOM: DW (gr) - AOM (gr) = OW (gr). }
$$

The entire weighing process was done using an analytical balance (Boeco, Germany; $0.01 \mathrm{gr}$ accuracy). In order to maintain nullification of the weights, all of the aluminum cores were weighed prior to measurement.

\section{Results}

Direct estimates of herbivore impact on turf algae were examined by comparison of the organic matter (ash free dry weight) among different treatments. The different treatments consisted in caged settlement plates (T0), noncaged settlement plates, and settlement plates that were removed from the cages and exposed to grazing for $2 \mathrm{~h}$ (T1) or $11 \mathrm{~h}$ (T2). In the first experiment, conducted in February 2008 , a significant difference was revealed between the caged plates and those that were exposed during the day, while no difference was shown between the two exposure time periods (one-way ANOVA, $P<0.01$, Tukey; Figure 2). Moreover, no significant difference was shown between the caged plates and the night-exposed plates (one-way ANOVA, $P>0.05$, Tukey; Figure 2). Significant differences were shown between the control noncaged plates and the rest of the treatments (one-way ANOVA, $P<0.01$, Tukey; Figure 2).

The second experiment, conducted in August 2008, revealed similar trends (Figure 3). Significant differences were shown between the caged plates and the plates exposed during the day for $11 \mathrm{~h}$ (Kruskal-Wallis test, $P<0.05$, Multiple Comparisons of Mean Ranks; Figure 3), while no significant difference was shown between the two exposure 


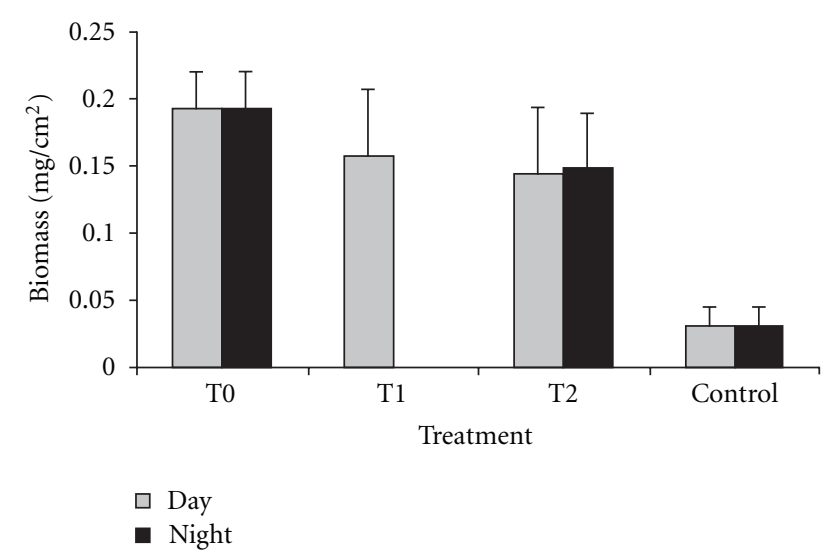

Figure 3: Organic matter as measured in August 2008. Treatments consisted in caged settlement plates (T0 $n=21$ ), noncaged settlement plates (out $n=20$ ), and settlement plates removed from the cages and exposed to grazing for $2 \mathrm{~h}(\mathrm{~T} 1 n=14)$ and $11 \mathrm{~h}$ (T2 $n=13$ ). Grey columns: day exposure, black columns: night exposure.

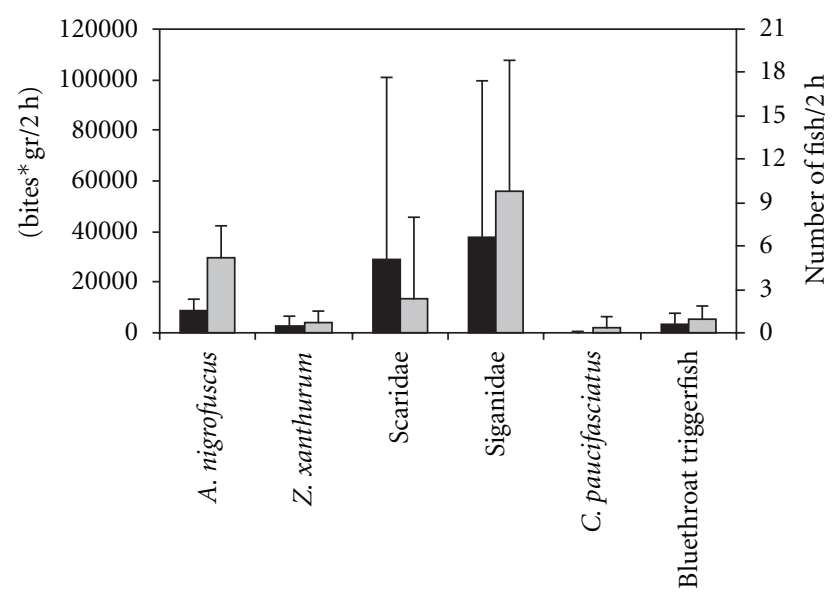

FIgURE 4: The number of bites normalized to fish weight, and the number of fish grazing on settlement plates. The number of bites normalized to fish weight, and the number of fish grazing on settlement plates exposed for 2 hours (T1), in February 2008. Black columns $=$ bites $*$ gr $(n=6)$, grey columns $=$ number of fish $(n=6)$.

time periods (Kruskal-Wallis test, $P>0.05$, Multiple Comparisons of Mean Ranks; Figure 3). Likewise, no significant difference was shown between the caged plates and the night-exposed plates (Kruskal-Wallis test, $P>0.05$, Multiple Comparisons of Mean Ranks; Figure 3). Significant differences were shown between the control non caged plates and the rest of the treatments (Kruskal-Wallis test, $P<0.05$, Multiple Comparisons of Mean Ranks; Figure 3).

Remote video recordings of herbivore bites were used to provide direct estimates of herbivore impact. The number of bites normalized to fish weight (gr) and the number of fish grazing on the settlement plates during the $2 \mathrm{~h}$ exposure period (T1) in February 2008 are presented in Figure 4. The $30 \%$ loss of organic material observed during this period

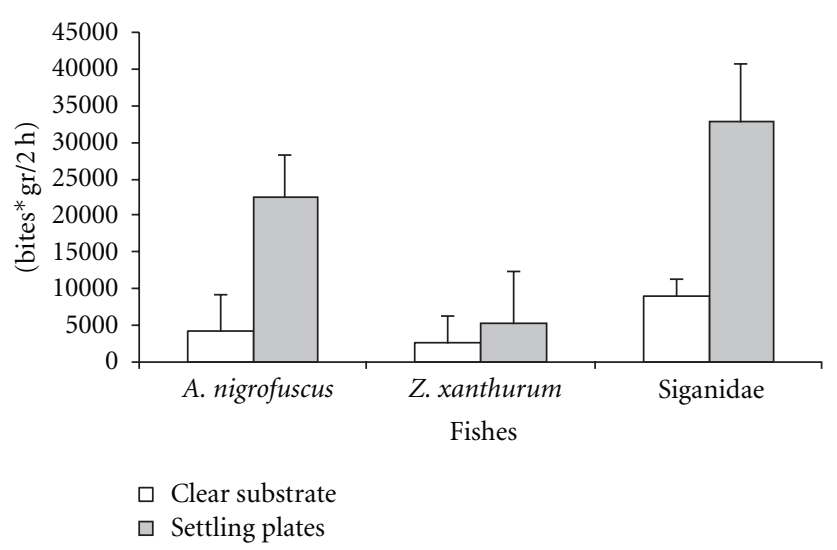

FIGURE 5: Bite rate (bites* gr/2 hr), of each recorded species, on settlement plates $(n=6)$ and on clear substrate $(n=4)$, during a 2-hour exposure period, in August 2008.

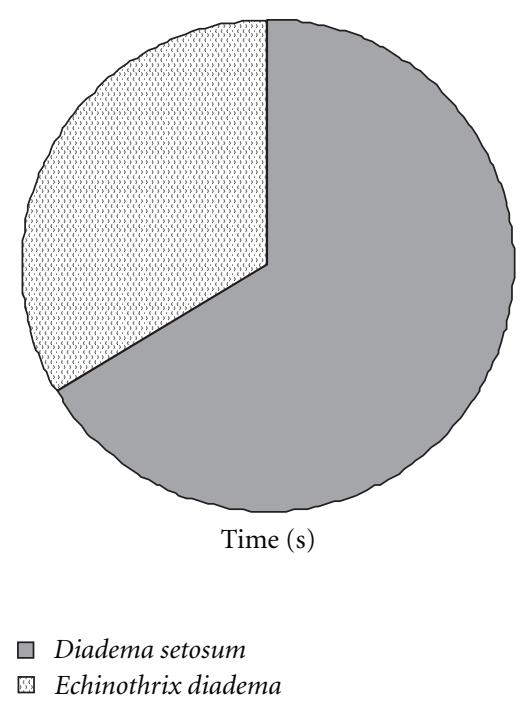

FIGURE 6: Night grazing observations during August 2008. Diadema setosum grazed for $66.3 \%$ of the total period of grazing, while Echinometra mathaei grazed for $33.6 \%$ of the total period.

(Figure 2) was a result of grazing, mainly by Siganidae, Scaridae, and Acanthurus nigrofuscus.

The grazing rates (bites*gr/2 h) of each recorded species on settlement plates and on clear substrate during the $2 \mathrm{~h}$ exposure period in August 2008 are presented in Figure 5. Fishes from the Siganidae family and the species A. nigrofuscus show a significantly higher grazing rate when grazing on settlement plates than on clear substrate (two-way ANOVA, $P<0.05$, Tukey; Figure 5).

Two echinoid species, Diadema setosum and Echinometra mathaei, were observed grazing during the nights of the August 2008 trial (Figure 6). D. setosum was observed grazing for $66.3 \%$ of the total time in which the settlement plates were grazed, while E. mathaei was found grazing for $33.6 \%$ of the total time.

A comparison between the surviving coral percentage of settlement plates that were grazed by echinoids and those 


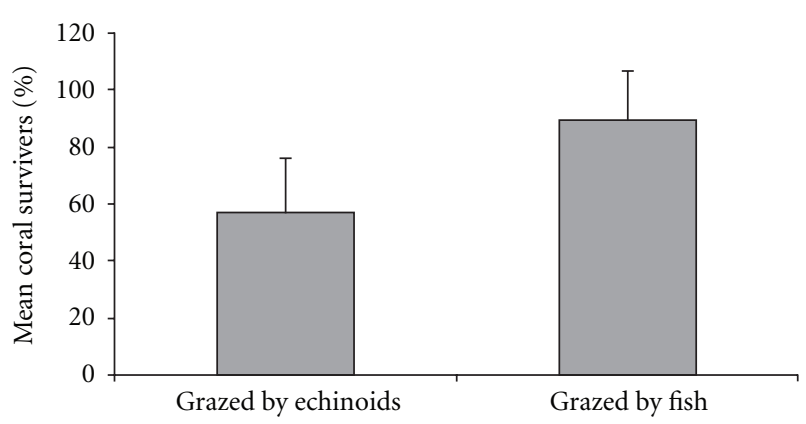

FIGURE 7: Surviving coral percentage of settlement plates that were grazed by echinoids $(n=4)$ and settlement plates that were grazed by fish $(n=8)$.

that were grazed by fish is presented in Figure 7. A significant difference was observed between treatments ( $t$-test, $P=$ 0.014; Figure 7).

\section{Discussion}

Algal takeover in coral reefs is becoming a prominent phenomenon, primarily induced by human activities, notably overfishing and eutrophication [3]. Successful recovery from algal takeover and other disturbances in coral reefs largely depends on the ability of coral larvae to settle and recruit $[12,34,35]$. Recovery by means of sexual reproduction may occur more slowly on reefs with abundant thick algal turfs than on reefs sparsely covered by algae [36]. Grazers have a profound effect on coral recruitment due to their consumption of algae, with a consequent reduction in competitive pressure $[10,11]$. However, because grazers can also eliminate newlysettled recruits [18], they can therefore inhibit coral recruitment. Our results shed light on this contrasting role of grazing effects on reef rehabilitation potential.

\subsection{Grazing Impact by Fish and Sea Urchins on Algal Biomass.} Overall, the findings from our experiments suggest that grazing by herbivorous fishes and invertebrates strongly affects algal cover and biomass. Algal biomass was about fourfold higher on caged plates than on noncaged plates. These results also support previous studies, which concluded that the maintenance of coral reefs may be largely due to the activities of fish and invertebrate herbivores, which prevent competitively superior algal populations from dominating open, sunlit substrates [37-40].

The present study reveals the predominant consumers of turf algae in Eilat reefs and differentiate, to the best of our knowledge for the first time, between the grazing impact exerted by day grazing of fishes, and night grazing by sea urchins. The cage experiment results show that the reduction in turf algae biomass was more intense during the day than the night. This indicates that the main grazing impact is due to the daily grazing by herbivore fishes, and to a lesser extent by the night grazing by sea urchins. A previous study of the Eilat coral reefs had shown different trends and suggested that grazing activity by sea urchins was the predominant factor regulating coverage of algae. In that study, however, no comparison was carried out between the grazing of sea urchins and that of fish [41]. Despite the former study having been carried out over 30 years ago, and its lack of quantitative data, it is well accepted that while there have been no dramatic fluctuations in the observed communities inhabiting the coral reef of Eilat, the reef has undergone degradation during the intervening period [42].

Grazing impact caused by herbivorous reef fishes was mainly due to representative species of three major families: rabbitfish (Siganidae), surgeonfish (Acanthuridae), and parrotfish (Scaridae). Our finding of the relatively low presence of grazers from the Scaridae family is not consistent with previous studies at other coral reef sites, which found that scarids make up a large portion of the total herbivory, with turf algae as their major diet component $[43,44]$. Although parrotfish species were shown to be relatively abundant, and have an important role in the bioerosion of the northern Red Sea reefs $[45,46]$, their grazing effect was shown to be relatively low in our study. Possible explanations for these differences could be related to disease or to competitive interaction with other herbivore species, but these aspects need further study.

Grazing impact of herbivorous reef invertebrates was mainly the result of two echinoid species: Diadema setosum and Echinometra mathaei, with D. setosum being the dominant observed grazing sea urchin. Microherbivores such as amphipods were not studied, since they were not expected to contribute substantially to total grazing impact [47]. These findings of herbivore grazing species are consistent with the published literature on various other coral reefs $[39,48]$. However, at other sites or biogeographical regions, seaurchins are considered to be the primary grazers and responsible for the control of algal abundance.

4.2. Grazing Effect on the Survival of Coral Recruits. Coral recruitment success is considered to be very low at many coral reef sites due to high mortality during the early life stages $[13,14]$. Our current findings provide direct evidence of the detrimental effects of grazing impact on coral recruits. The results clearly show that the survival rates of coral recruits on settlement plates grazed by sea urchins were significantly lower than those on the plates grazed by fish.

Direct negative effects of herbivorous fishes on corals are widely debated. Observations by Birkeland [49] in the tropical Eastern Pacific indicate that herbivorous fishes actively avoid consuming juvenile corals larger than a few millimeters in size. A field study by Bruggemann et al. [50] concluded that "Living coral is rarely eaten by scarids, and largely escapes erosion by grazing." In contrast, Randall [51] and Bak and Engle [20] reported that grazing fishes damaged juvenile corals.

Only two representatives of the predominant corallivore families were observed feeding from the plates: the crown butterflyfish Chaetodon paucifasciatus and the blue-throat triggerfish Sufflamen albicaudatus. Although these fish families have been documented as exerting obvious direct effects on reef corals $[39,51]$, these two specific species are known to 
feed not only on corals but also on algae and benthic invertebrates [52]. Moreover, the number of these fishes observed feeding was relatively low, and their grazing impact was negligible. This observation could be due to biogeographical differences. Although numerous studies conducted on various coral reefs have focused on the effects of corallivores, showing their contrasting effects on the survival of juvenile corals, they have concentrated on parrotfish as the main fish responsible for coral predation $[36,39,51,53,54]$. Parrotfish were not observed grazing on our studied corals. The presence of algae around the juvenile corals [36] may conduce to reducing the risk of predation by parrotfishes [36].

Echinoids exert a direct negative effect on corals by removing recently settled juveniles [55]. Additionally, several echinoid species such as diadematid sea urchins have been found to feed occasionally on live coral [56-58]. Nevertheless, the direct effects of $D$. antillarum predation on coralreef community structure were not considered significant in either of the latter studies [39]. Sammarco [59] found that grazing by $D$. antillarum influenced the survivorship and abundance of newly settled corals as a result of both the direct effects of grazing on settled coral spat and the indirect effect of modifying competitive interactions between algae and corals.

The relatively short duration $(24 \mathrm{~h})$ of the present study and limited temporal and spatial replications can only provide a rough estimate of the overall effect of predation and algal grazing on coral recruit survival. However, the obtained data suggest that corallivores have a relatively minor effect on the survival of coral recruits, whereas herbivorous grazing has a considerable effect on their survival, mainly due to the direct negative effects of $D$. setosum grazing.

Importantly, spatial variation in predation intensity, both herbivory and corallivory, is well documented among sites, habitats, and depth zones $[10,17,60]$. Hence the effects of predation and algal grazing on coral recruit survival cannot be generalized to all reef sites and habitats and will depend on the specific traits of the benthic biota composition and densities of fishes and invertebrates involved.

Here we have revealed a unique differentiation of the grazing effects exerted by fishes and by sea urchins, reflecting their respective contributions to coral reef resilience. Herbivore fishes are fundamental in modeling the benthic communities of coral reefs in Eilat and are crucial for the reefs' resilience. The combined effect of high grazing pressure on algal turfs and minor negative effects on the survival of coral recruits may be a critical key for coral reef resilience. Moreover, these findings support the idea that reestablishing populations of herbivore fishes on degraded reefs might initiate a phase shift away from the algal-dominated state of reefs towards a state that would promote coral recruitment. Conversely, sea urchins were found to exert an adverse effect on corals and algae. Their low grazing pressure on the turf, coupled with the increased impediment to coral recruits, could negatively affect the balance between corals and algae, consequently eroding coral reef resilience.

Accurate assessments of grazing impact on algal biomass and coral recruitment are hard to acquire due to various methodological constraints (e.g., use of experimental rather than natural substrates) and limited temporal and spatial replications. Despite these limitations, our findings provide direct evidence of the potential effects of different functional groups of herbivore grazers (i.e., differential effects of sea urchins versus fish) on the resilience of coral reefs. These findings contribute to the overall understanding of the factors influencing turf-algae establishment and proliferation and the survival of coral recruits in the coral reefs of Eilatknowledge crucial for coral reef conservation and the implementation of sound management and restoration measures.

\section{Acknowledgments}

This study was funded by the Red Sea Marine Peace Park (RSMPP) program of the US Agency for International Development-Middle Eastern Regional Cooperation (USAID-MERC) to A. Abelson. The authors thank Ms N. Paz for her editorial assistance. We also thank Mr. S. Martinez for his assistance in data collection and the directors and staff of the Interuniversity Institute (IUI) in Eilat.

\section{References}

[1] M. Nyström, C. Folke, and F. Moberg, "Coral reef disturbance and resilience in a human-dominated environment," Trends in Ecology and Evolution, vol. 15, no. 10, pp. 413-417, 2000.

[2] T. P. Hughes, N. A. J. Graham, J. B. C. Jackson, P. J. Mumby, and R. S. Steneck, "Rising to the challenge of sustaining coral reef resilience," Trends in Ecology and Evolution, vol. 25, no. 11, pp. 633-642, 2010.

[3] D. R. Bellwood, T. P. Hughes, C. Folke, and M. Nyström, "Confronting the coral reef crisis," Nature, vol. 429, no. 6994, pp. 827-833, 2004.

[4] C. L. Birrell, Influences of Benthic Algae on Coral Settlement and Post-Settlement Survival: Implications for the Recovery of Disturbed and Degraded Reefs, James Cook University, Townsville, Australia, 2003.

[5] L. J. McCook, J. Jompa, and G. Diaz-Pulido, "Competition between corals and algae on coral reefs: a review of evidence and mechanisms," Coral Reefs, vol. 19, no. 4, pp. 400-417, 2001.

[6] L. J. McCook, "Macroalgae, nutrients and phase shifts on coral reefs: scientific issues and management consequences for the Great Barrier Reef," Coral Reefs, vol. 18, no. 4, pp. 357-367, 1999.

[7] M. M. Littler, D. S. Littler, and B. L. Brooks, "Harmful algae on tropical coral reefs: bottom-up eutrophication and top-down herbivory," Harmful Algae, vol. 5, no. 5, pp. 565-585, 2006.

[8] J. Lubchenco and S. D. Gaines, "A unified approach to marine plant-herbivore interactions. I. populations and communities," Annual Reviews in Ecology and Systematics, vol. 12, no. 1, pp. 405-437, 1981.

[9] T. R. Mcclanahan, A. T. Kamukuru, N. A. Muthiga, M. Gilagabher Yebio, and D. Obura, "Effect of sea urchin reductions on algae, coral, and fish populations," Conservation Biology, vol. 10, no. 1, pp. 136-154, 1996.

[10] P. W. Glynn, "Feeding ecology of selected coral-reef macroconsumers: patterns and effects on coral community structure," Ecosystems of the World, vol. 25, pp. 365-400, 1990. 
[11] M. E. Hay, "The ecology and evolution of seaweed-herbivore interactions on coral reefs," Coral Reefs, vol. 16, no. 1, pp. S67S76, 1997.

[12] J. M. West and R. V. Salm, "Resistance and resilience to coral bleaching: implications for coral reef conservation and management," Conservation Biology, vol. 17, no. 4, pp. 956967, 2003.

[13] R. H. Richmond and C. L. Hunter, "Reproduction and recruitment of corals: comparisons among the Caribbean, the Tropical Pacific, and the Red Sea," Oldendorf, vol. 60, no. 1, pp. 185-203, 1990, Marine ecology progress series.

[14] A. Abelson, R. Olinky, and S. Gaines, "Coral recruitment to the reefs of Eilat, Red Sea: temporal and spatial variation, and possible effects of anthropogenic disturbances," Marine Pollution Bulletin, vol. 50, no. 5, pp. 576-582, 2005.

[15] T. P. Hughes, "Catastrophes, phase shifts, and large-scale degradation of a Caribbean coral reef," Science, vol. 265, no. 5178, pp. 1547-1551, 1994.

[16] S. M. Lewis, "The role of herbivorous fishes in the organization of a Caribbean reef community," Ecological Monographs, vol. 56, no. 3, pp. 183-200, 1986.

[17] M. W. Miller and M. E. Hay, "Effects of fish predation and seaweed competition on the survival and growth of corals," Oecologia, vol. 113, no. 2, pp. 231-238, 1998.

[18] M. W. Miller, E. Weil, and A. M. Szmant, "Coral recruitment and juvenile mortality as structuring factors for reef benthic communities in Biscayne National Park, USA," Coral Reefs, vol. 19, no. 2, pp. 115-123, 2000.

[19] L. Penin, F. Michonneau, A. H. Baird et al., "Early postsettlement mortality and the structure of coral assemblages," Marine Ecology Progress Series, vol. 408, pp. 55-64, 2010.

[20] R. P. M. Bak and M. S. Engel, "Distribution, abundance and survival of juvenile hermatypic corals (Scleractinia) and the importance of life history strategies in the parent coral community," Marine Biology, vol. 54, no. 4, pp. 341-352, 1979.

[21] S. J. Box and P. J. Mumby, "Effect of macroalgal competition on growth and survival of juvenile Caribbean corals," Marine Ecology Progress Series, vol. 342, pp. 139-149, 2007.

[22] P. J. Edmunds, J. F. Bruno, and D. B. Carlon, "Effects of depth and microhabitat on growth and survivorship of juvenile corals in the Florida Keys," Marine Ecology Progress Series, vol. 278, pp. 115-124, 2004.

[23] P. J. Mumby, C. P. Dahlgren, A. R. Harborne et al., "Fishing, trophic cascades, and the process of grazing on coral reefs," Science, vol. 311, no. 5757, pp. 98-101, 2006.

[24] J. F. Bruno, H. Sweatman, W. F. Precht, E. R. Selig, and V. G. W. Schutte, "Assessing evidence of phase shifts from coral to macroalgal dominance on coral reefs," Ecology, vol. 90, no. 6, pp. 1478-1484, 2009.

[25] K. Bahartan, M. Zibdah, Y. Ahmed, A. Israel, I. Brickner, and A. Abelson, "Macroalgae in the coral reefs of Eilat (Gulf of Aqaba, Red Sea) as a possible indicator of reef degradation," Marine Pollution Bulletin, vol. 60, no. 5, pp. 759-764, 2010.

[26] R. J. Fox and D. R. Bellwood, "Direct versus indirect methods of quantifying herbivore grazing impact on a coral reef," Marine Biology, vol. 154, no. 2, pp. 325-334, 2008.

[27] C. S. Mantyka and D. R. Bellwood, "Direct evaluation of macroalgal removal by herbivorous coral reef fishes," Coral Reefs, vol. 26, no. 2, pp. 435-442, 2007.

[28] N. Odat, "Length-weight relationship of fishes from coral reefs along the coastline of Jordan (Gulf of Aqaba)," NAGA, vol. 26, no. 1, pp. 9-10, 2003.
[29] M. Kulbicki, N. Guillemot, and M. Amand, "A general approach to length-weight relationships for New Caledonian lagoon fishes," Cybium, vol. 29, no. 3, pp. 235-252, 2005.

[30] R. Froese, D. Pauly, and M. International Center for Living Aquatic Resources, "FishBase a global information system on fishes," FishBase, 2010.

[31] B. a. Y. L. Rinkevich, "Reproduction of the Red-Sea coral Stylophora-Pistillata .1. Gonads and planulae," Marine Ecology-Progress, vol. 2, pp. 133-144, 1979.

[32] A. H. Baird, A. Salih, and A. Trevor-Jones, "Fluorescence census techniques for the early detection of coral recruits," Coral Reefs, vol. 25, no. 1, pp. 73-76, 2006.

[33] G. A. Piniak, N. D. Fogarty, C. M. Addison, and W. J. Kenworthy, "Fluorescence census techniques for coral recruits," Coral Reefs, vol. 24, no. 3, pp. 496-500, 2005.

[34] G. P. Jones, M. I. McCormick, M. Srinivasan, and J. V. Eagle, "Coral decline threatens fish biodiversity in marine reserves," Proceedings of the National Academy of Sciences of the United States of America, vol. 101, no. 21, pp. 8251-8253, 2004.

[35] C. L. Birrell, L. J. McCook, B. L. Willis, and G. A. Diaz-Pulido, "Effects of benthic algae on the replenishment of corals and the implications for the resilience of coral reefs," Oceanography and Marine Biology, vol. 46, pp. 25-63, 2008.

[36] D. E. Venera-Ponton, G. Diaz-Pulido, L. J. McCook, and A. Rangel-Campo, "Macroalgae reduce growth of juvenile corals but protect them from parrotfish damage," Marine Ecology Progress Series, vol. 421, pp. 109-115, 2011.

[37] J. C. Ogden and P. S. Lobel, "The role of herbivorous fishes and urchins in coral reef communities," Environmental Biology of Fishes, vol. 3, no. 1, pp. 49-63, 1978.

[38] M. H. Ledlie, N. A. J. Graham, J. C. Bythell et al., "Phase shifts and the role of herbivory in the resilience of coral reefs," Coral Reefs, vol. 26, no. 3, pp. 641-653, 2007.

[39] C. Birkeland, Life and Death of Coral Reefs, Chapman \& Hall, New York, NY, USA, 1997.

[40] D. R. Bellwood, T. P. Hughes, and A. S. Hoey, "Sleeping functional group drives coral-reef recovery," Current Biology, vol. 16, no. 24, pp. 2434-2439, 2006.

[41] Y. Benayahu and Y. Loya, "Seasonal occurrence of benthicalgae communities and grazing regulation by sea urchins at the coral reefs of Eilat, Red Sea," in Proceedings of the 3rd International Coral Reef Symposium, Miami, Fla, USA, 1977.

[42] Y. Loya, The Coral Reefs of Eilat-Past, Present and Future: Three Decades of Coral Community Structure Studies, Coral health and disease, Springer, Berlin, Germany, 2004.

[43] G. Tolentino-Pablico, N. Bailly, R. Froese, and C. Elloran, "Seaweeds preferred by herbivorous fishes," Journal of Applied Phycology, vol. 20, no. 5, pp. 933-938, 2008.

[44] D. G. Ochavillo, P. I. Dixon, and P. M. Alino, The Daily Food Ration of Parrotfishes in the Fringing Reefs of Bolinao, Northwestern Philippines, Pangasinan, Philippines, 1992.

[45] M. A. Alwany, E. Thaler, and M. Stachowitsch, "Parrotfish bioerosion on Egyptian Red Sea reefs," Journal of Experimental Marine Biology and Ecology, vol. 371, no. 2, pp. 170-176, 2009.

[46] Y. Bouchon-Navaro and M. L. Harmelin-Vivien, "Quantitative distribution of herbivorous reef fishes in the Gulf of Aqaba (Red Sea)," Marine Biology, vol. 63, no. 1, pp. 79-86, 1981.

[47] R. C. Carpenter, "Partitioning herbivory and its effects on coral reef algal communities," Ecological Monographs, vol. 56, no. 4, pp. 345-363, 1986.

[48] J. H. Choat, "The biology of herbivorous fishes on coral reefs," in The Ecology of Fishes on Coral Reefs, P. F. Sale, Ed., pp. 120$155,1991$. 
[49] C. Birkeland, "The importance of rate of biomass accumulation in early successional stages of benthic communities to the survival of coral recruits," in Proceedings of the $3 \mathrm{rd}$ International Coral Reef Symposium, 1977.

[50] J. H. Bruggemann, A. M. Van Kessel, J. M. Van Rooij, and A. M. Breeman, "Bioerosion and sediment ingestion by the caribbean parrotfish Scarus vetula and Sparisoma viride: implications of fish size, feeding mode and habitat use," Oldendorf, vol. 134, no. 1-3, pp. 59-71, 1996, Marine Ecology Progress Series.

[51] J. E. Randall, "The effect of fishes on coral reefs," 1974.

[52] F. Myers and E. L. Robert, Coral Reef Guide Red Sea, H. Brocklehurst, Ed., HarperCollins, 2004.

[53] R. D. Rotjan and J. L. Dimond, "Discriminating causes from consequences of persistent parrotfish corallivory," Journal of Experimental Marine Biology and Ecology, vol. 390, no. 2, pp. 188-195, 2010.

[54] P. J. Mumby, "Herbivory versus corallivory: are parrotfish good or bad for Caribbean coral reefs?” Coral Reefs, vol. 28, no. 3, pp. 683-690, 2009.

[55] P. A. Hutchings, "Biological destruction of coral reefs," Coral Reefs, vol. 4, no. 4, pp. 239-252, 1986.

[56] R. P. M. Bak and G. van Eys, "Predation of the sea urchin Diadema antillarum Philippi on living coral," Oecologia, vol. 20, no. 2, pp. 111-115, 1975.

[57] P. J. Herring, "Observations on the distribution and feeding habits of some littoral echinoids from Zanzibar," Journal of Natural History, vol. 6, pp. 169-175, 1972.

[58] R. C. Carpenter, "Grazing by Diadema antillarum (Philippi) and its effects on the benthic algal community," Journal of Marine Research, vol. 39, no. 4, pp. 749-765, 1981.

[59] P. W. Sammarco, "Diadema and its relationship to coral spat mortality: grazing, competition, and biological disturbance," Journal of Experimental Marine Biology and Ecology, vol. 45, no. 2, pp. 245-272, 1980.

[60] M. M. Littler, P. R. Taylor, and D. S. Littler, "Complex interactions in the control of coral zonation on a Caribbean reef flat," Oecologia, vol. 80, no. 3, pp. 331-340, 1989. 

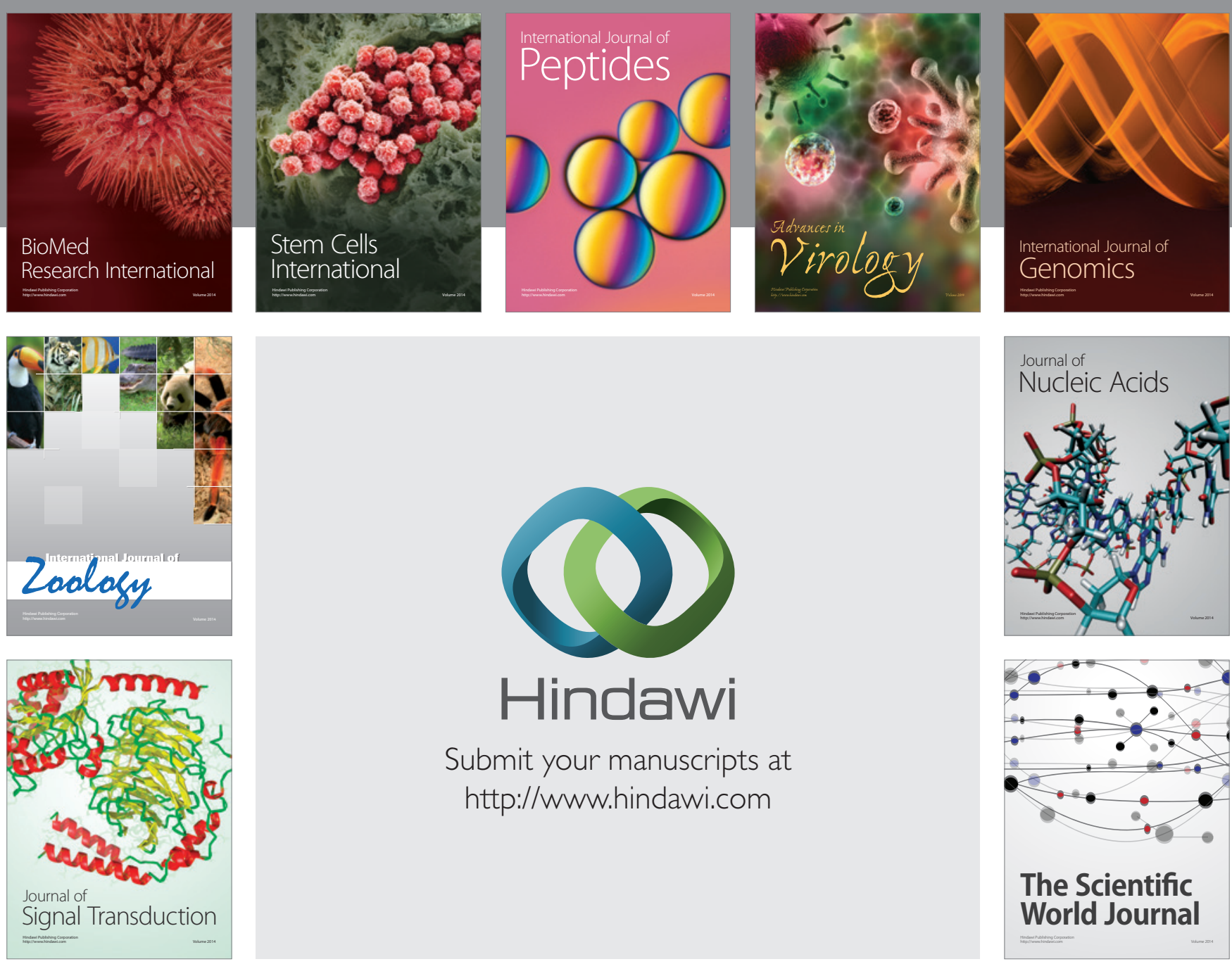

Submit your manuscripts at

http://www.hindawi.com
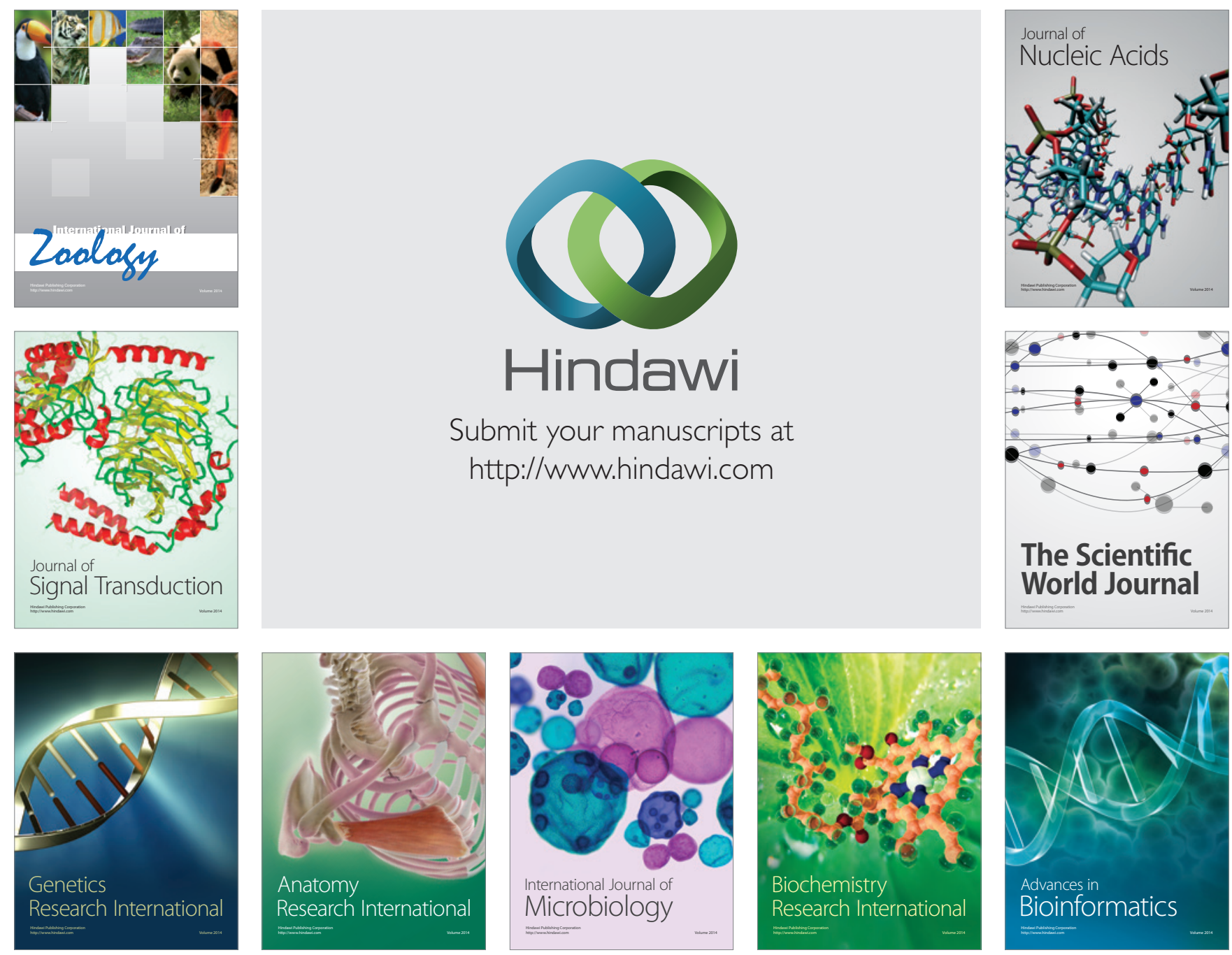

The Scientific World Journal
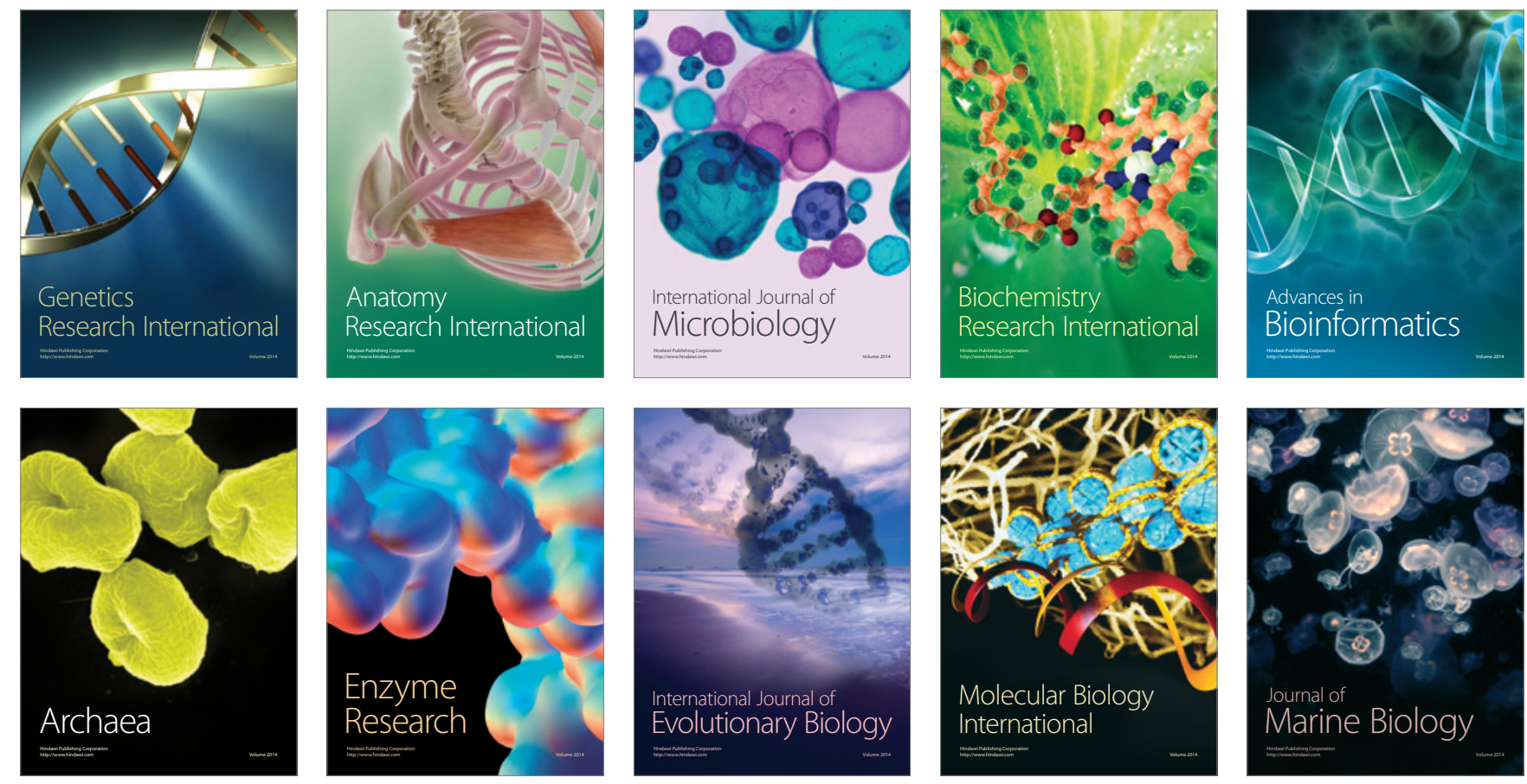